MATEC Web of Conferences 2, 02001 (2012)

DOI: $10.1051 /$ matecconf $/ 20120202001$

C Owned by the authors, published by EDP Sciences, 2012

\title{
Performance of externally CFRP confined RC columns with changes in thickness of the wrap, slenderness of the column and shape of the section
}

\author{
N. Chikh ${ }^{1}$, H. Mesbah ${ }^{2}$, M. Gahmous ${ }^{3}$ and R. Benzaid ${ }^{4}$ \\ ${ }^{1}$ LMDC, Department of Civil Engineering, University of Mentouri Constantine, Constantine, Algeria \\ ${ }^{2}$ DLGCGM, Department of Civil Engineering, INSA of Rennes, Rennes, Cedex 35043, France \\ ${ }^{3}$ Department of Civil Engineering, University of Oum El-Bouaghi, Oum El-Bouaghi, Algeria \\ ${ }^{4}$ LMDC, Department of Geology, University of Jijel, Jijel, Algeria
}

\begin{abstract}
The present study deals with the analysis of experimental results, in terms of load carrying capacity and strains, obtained from tests on reinforced concrete (RC) columns, strengthened with external carbon fiber reinforced polymer (CFRP) sheets. The experimental parameters include: number of wrap layers, slenderness of the columns (L/a or L/D) and shape of the section (circular and square). A total of 48 specimens were subjected to axial compression. All test specimens were loaded to failure in axial compression. Compressive stress, axial and hoop strains have been recorded to evaluate the stress-strain relationship, ultimate strength, stiffness, and ductility of the specimens. Results clearly demonstrate that composite wrapping can enhance the structural performance of RC columns in terms of both maximum strength and ductility. The effects of test parameters are evidenced and compared.
\end{abstract}

\section{Introduction}

During the last decade, the use of FRP composites has been successfully promoted for external confinement of reinforced concrete (RC) columns all over the world. Several studies on the performance of FRP wrapped columns have been conducted, using both experimental and analytical approaches [1](H. Saadatmanesh et al., 1994); [2](A. Nanni and N.M. Bradford, 1995); [3](V.M. Karbhari and Y. Gao, 1997); [4](A. Miraman et al., 1998); [5](G. Campione and N. Miraglia, 2004); [6](J. Berthet et al., 2005). Such strengthening technique has proved to be very effective in enhancing their ductility and axial load capacity. Most of the available experimental data regarding FRP-confined columns have been generated from tests on small-scale concrete cylinders with normal strength. The data available for columns of square or rectangular cross sections have increased over recent years but are still limited [7](P. Rochette et al., 2000), [8](O. Chaallal et al., 2003); [9](Y.A. Al-Salloum, 2007). Also the validation of these results and their applicability to large-scale RC columns is of great practical interest. Published work in this field is relatively few [10](M. Thériault et al., 2004), [11](J.L. Pan et al., 2007). More research investigation is needed on this subject to study the effect of slenderness of concrete columns with higher strength. 
This study presents a comprehensive experimental investigation on the behavior of axially loaded circular and square reinforced columns strengthened with CFRP wrap. A total of 48 concrete specimens were tested under axial compression. The data recorded included the compressive loads, axial strains, and radial strains. The parameters considered are the number of composite layers and slenderness ratio of the column L/D for circular shape and L/a for square shape.

\section{Experimental program}

The concrete mix used to prepare testing specimens has an average strength of $50 \mathrm{MPa}$. The carbonfiber sheets used were the SikaWrap-230C product, a unidirectional wrap. The Sikadur-330 epoxy resin was used to bond the carbon fabrics over the square columns. Eight series of experiments were performed to investigate the behaviour of PC and RC columns confined by CFRP composite. Table 1 summarizes the specimens involved in the experimental program. For all RC specimens the diameter of longitudinal and transverse reinforcing steel bars were respectively $12 \mathrm{~mm}$ and $8 \mathrm{~mm}$. The longitudinal steel ratio was constant for all specimens and equal to $2.25 \%$. The yield strength of the longitudinal and transversal reinforcement was $500 \mathrm{MPa}$ and $235 \mathrm{MPa}$, respectively.

The specimen notations are as follows. The first two letters refer to the cross section shape: $\mathrm{C}$ for circular and $\mathrm{S}$ for square, followed by type of concrete: PC for plain concrete and $\mathrm{RC}$ for reinforced concrete. The next letter indicates the slenderness ratio: $x$ for $\mathrm{L} / \mathrm{a}=2$ (or $\mathrm{L} / \mathrm{D}=2$ ), y for $\mathrm{L} / \mathrm{a}=4$ (or $\mathrm{L} / \mathrm{D}=5.08$ ) and $\mathrm{z}$ for $\mathrm{L} / \mathrm{a}=7.14$ (or $\mathrm{L} / \mathrm{D}=6.45$ ). The last number specifies the number of layers.

Table 1. Details of test specimens.

\begin{tabular}{|c|c|c|c|c|}
\hline $\begin{array}{c}\text { Specimen } \\
\text { designation }\end{array}$ & $\begin{array}{l}\text { Slender ratio } \\
\mathrm{L} / \mathrm{D} \text { or } \mathrm{L} / \mathrm{a}\end{array}$ & $\begin{array}{c}\text { Nominal dimensions } \\
(\mathrm{D} \times \mathrm{L} \text { or } \mathrm{a} \times \mathrm{a} \times \mathrm{L})[\mathrm{mm}]\end{array}$ & $\begin{array}{c}\text { Number of } \\
\text { layers }\end{array}$ & $\begin{array}{l}\text { Number of } \\
\text { specimens }\end{array}$ \\
\hline CPC. $\mathrm{x} 0$ & 2 & $160 \times 320$ & 0 & 2 \\
\hline CPC. $x 1$ & 2 & $160 \times 320$ & 1 & 2 \\
\hline CPC. $x 3$ & 2 & $160 \times 320$ & 3 & 2 \\
\hline CRC. $\mathrm{x} 0$ & 2 & $160 \times 320$ & 0 & 2 \\
\hline CRC. $x 1$ & 2 & $160 \times 320$ & 1 & 2 \\
\hline CRC. $x 3$ & 2 & $160 \times 320$ & 3 & 2 \\
\hline CRC. y0 & 5.08 & $197 \times 1000$ & 0 & 2 \\
\hline CRC. y1 & 5.08 & $197 \times 1000$ & 1 & 2 \\
\hline CRC. y3 & 5.08 & $197 \times 1000$ & 3 & 2 \\
\hline CRC. z0 & 6.45 & $155 \times 1000$ & 0 & 2 \\
\hline CRC. z1 & 6.45 & $155 \times 1000$ & 1 & 2 \\
\hline CRC. z3 & 6.45 & $155 \times 1000$ & 3 & 2 \\
\hline SPC. $\mathrm{x} 0$ & 2 & $140 \times 140 \times 280$ & 0 & 2 \\
\hline SPC. $x 1$ & 2 & $140 \times 140 \times 280$ & 1 & 2 \\
\hline SPC. $x 3$ & 2 & $140 \times 140 \times 280$ & 3 & 2 \\
\hline SRC. $\mathrm{x} 0$ & 2 & $140 \times 140 \times 280$ & 0 & 2 \\
\hline SRC. $x 1$ & 2 & $140 \times 140 \times 280$ & 1 & 2 \\
\hline SRC. $x 3$ & 2 & $140 \times 140 \times 280$ & 3 & 2 \\
\hline SRC. y0 & 4 & $140 \times 140 \times 560$ & 0 & 2 \\
\hline SRC. y1 & 4 & $140 \times 140 \times 560$ & 1 & 2 \\
\hline SRC. y3 & 4 & $140 \times 140 \times 560$ & 3 & 2 \\
\hline SRC. z0 & 7.14 & $140 \times 140 \times 1000$ & 0 & 2 \\
\hline SRC. $z 1$ & 7.14 & $140 \times 140 \times 1000$ & 1 & 2 \\
\hline SRC. $z 3$ & 7.14 & $140 \times 140 \times 1000$ & 3 & 2 \\
\hline
\end{tabular}


After concrete columns were fully cured, FRP wrapping was performed according to the procedure specified by the manufacturer. Specimens were loaded under a monotonic uni-axial compression load up to failure. The load was applied at a rate corresponding to $0.24 \mathrm{MPa} / \mathrm{s}$ and was recorded with an automatic data acquisition system. Axial and lateral strains were measured using extensometers. The instrumentation included either lateral or radial linear variable differential transducer (LVDT) placed in the form of a square frame or a hoop at the mid-height of the specimens. Measurement devices also included 3 vertical LVDTs to measure the average axial strains. The test setup for the various specimens is shown in Figure 1.
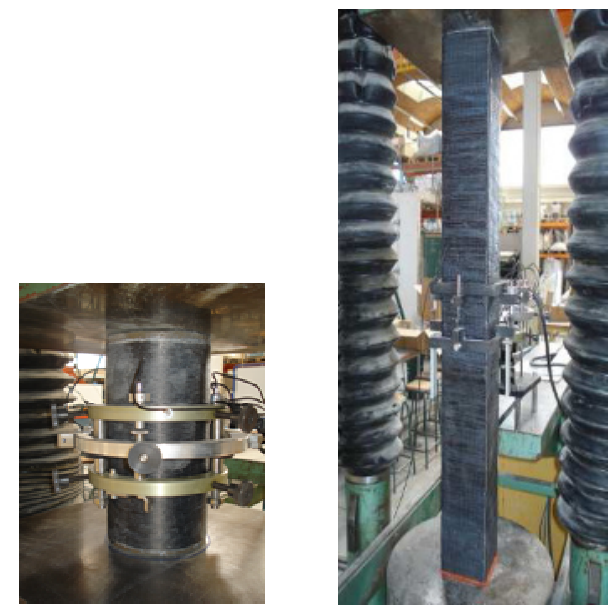

Fig. 1. Test setup

\section{Test results and discussion}

Compression behavior of the CFRP wrapped specimens was mostly similar in each series in terms of stress-strain curves and failure modes of the specimens. No lateral deflection was observed during all tests. All confined concrete columns failed by fracture of the composite wrap in a sudden and explosive way preceded by typical creeping sounds. Regarding square columns, failure occurred at one of the corners, because of the high stress concentration at these locations, Figure 2. For short specimens, the fiber rupture starts mainly in their central zone and then propagates towards other sections. Regarding slender specimens, the collapse was mostly concentrated in their end regions, indicating that the greater the slender ratio, the smaller the area of CFRP ruptured.

At ultimate load, when confinement action was no longer provided due to FRP fracture, the internal steel started buckling and the crushed concrete fell down between the fractured FRP. This indicates that the concrete core is significantly damaged (but yet confined) even before reaching ultimate load.

For all confined specimens, delamination was not observed at the overlap location of the jacket, which confirmed the adequate stress transfer over the splice. The strain values observed for the jacket tensile failure were quite lower that the FRP failure strain, as many authors have already published.

Representative stress-strain curves for each series of tested CFRP-wrapped specimens are reported in Figure 3 for circular specimens and in Figure 4 for square specimens. These figures give the axial stress versus the axial and lateral strains for specimens with zero, 1 and 3 layers of CFRP wrap considering various slenderness ratios.

At ultimate load, when confinement action was no longer provided due to FRP fracture, the internal steel started buckling and the crushed concrete fell down between the fractured FRP. This 
indicates that the concrete core is significantly damaged (but yet confined) even before reaching ultimate load.
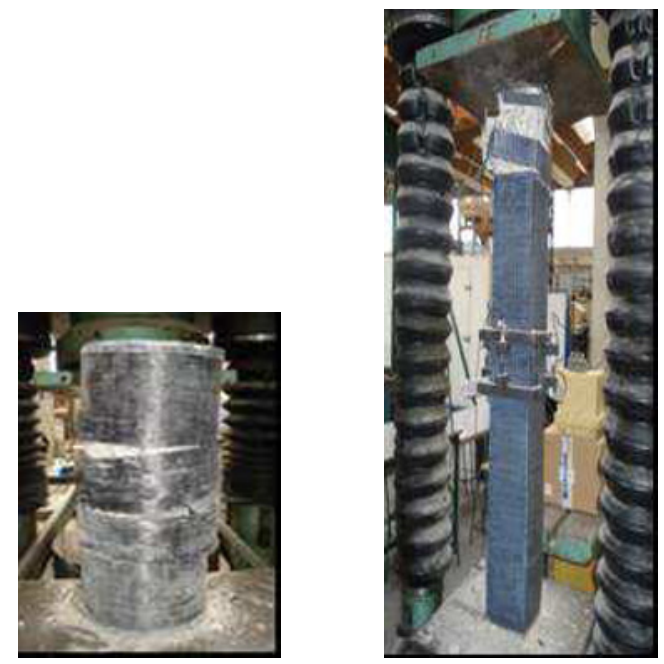

Fig. 2. Failure of CFRP confined specimens

\subsection{Stress-strain response}

All CFRP strengthened specimens showed a typical bilinear trend. The first zone is essentially a linear response governed by the stiffness of the unconfined concrete, which indicates that no confinement is activated in the CFRP wraps since the lateral strains in the concrete are very small. Hence the confined and the unconfined specimens behave in the same manner, irrespective of the number of layers. After reaching the maximum load point, the unconfined concrete specimens show a sudden drop in stiffness and strength. The increase of load produces large lateral expansions, and consequently the CFRP wrap reacts accordingly and a confining action is created on the concrete core. It should be noted that the confinement pressure is activated at higher load (around $70 \% \div 80 \%$ of the ultimate value). In the case of circular columns the section is fully confined, therefore the capacity of confining pressure is able to limit the effects of the deteriorated concrete core, which allows reaching higher stresses. Instead in the cases of square sections, the confining action is mostly limited at the corners, producing therefore a confining pressure not sufficient to overcome the effect of concrete degradation. In the second zone, the concrete is fully cracked and the activated CFRP confinement provides additional load carrying capacity by keeping the concrete core intact. The stress-strain curve here increases linearly up to failure. The stiffness of the specimen in this zone depends on the modulus of elasticity of the CFRP material and on the level of confinement. No distinct post behaviour is observed for specimens with higher slenderness ratio. On overall, both ultimate compressive strength and ultimate strain are variably enhanced depending on the number of layers and the slenderness ratio.

\subsection{Effect of CFRP Strengthening Ratio}

Test results illustrated in Figures 3 and 4 indicate that FRP-confinement can significantly enhance the ultimate strengths and strains of the specimens. As observed for circular columns, the average ratio of concrete strength of confined to unconfined member $\left(\mathrm{f}_{\mathrm{cc}}{ }_{\mathrm{cc}} / \mathrm{f}_{\mathrm{co}}\right.$ ) increases by $14 \% \div 45 \%$ for 1 ply, and by $60 \% \div 72 \%$ for 3 plies of CFRP jackets, whereas the enhancement in the bearing capacity 


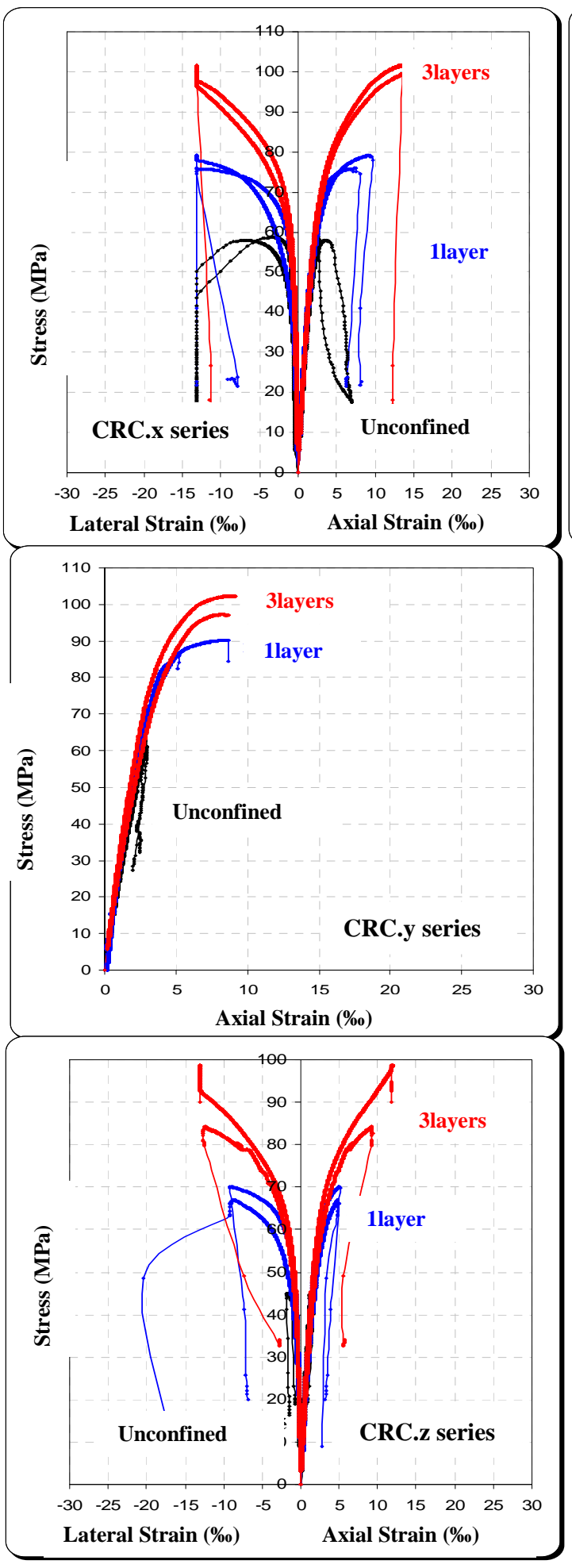

Fig.3. Stress-strain curves for circular columns

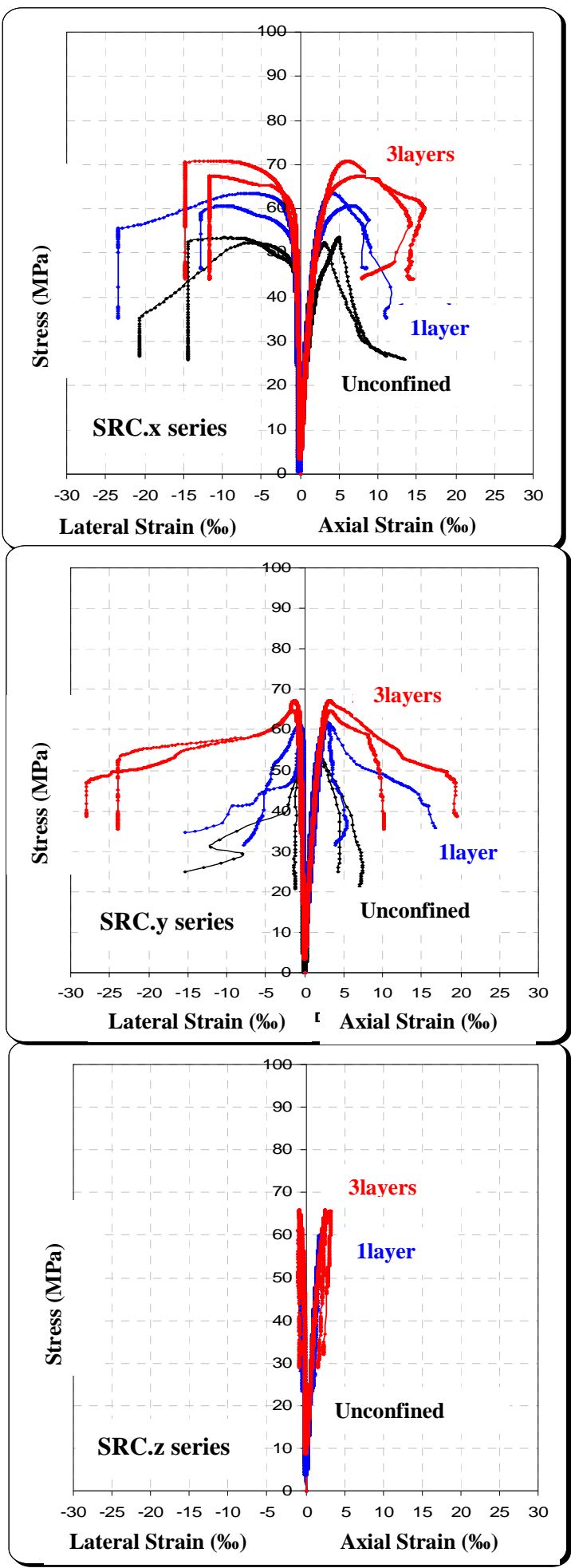

Fig.4. Stress-strain curves for square columns 
for square columns was lower as the recorded increases were only $8 \% \div 24 \%$ for 1 ply, and $20 \% \div 35 \%$ for 3 plies of CFRP jackets. The axial strains corresponding to confined circular specimens $\left(\varepsilon_{\mathrm{cc}}\right)$, were higher than that of unconfined concrete $\left(\varepsilon_{\mathrm{c} 0}\right)$ by $50 \% \div 180 \%$ for 1 layer and by $200 \% \div 450 \%$ for 3 layers of CFRP wrap, respectively. The increase was relatively moderate for square specimens as the enhancement in the ultimate axial deformations display an increase of $18 \% \div 55 \%$ for 1 layer and $50 \% \div 110 \%$ for 3 layers of CFRP wrap, respectively. As expected, these results clearly show that strength and ductility improvement were more important for circular column because its section is fully confined. It should be emphasized that the presence of quite sharp corners in all tested CFRP jacketed square columns produced a cutting effect on confining sheets and hence affected the rate of enhancement in their load carrying and deformation capacities.

\subsection{Effect of slenderness ratio}

The comparison of results recorded from wrapped $\mathrm{RC}$ specimens having equal cross section, shows that the increase of the slenderness ratio within the range of values considered $(\cong 2 \div 7)$ leads on overall to a small decrease in the load carrying capacity and a moderate reduction in the axial deformation. In this respect, it is suggested to consider higher values for the slenderness ratio $(>12)$ in order to investigate its relevant influence in an appropriate manner.

\section{Conclusions}

The results of an experimental investigation on the performance of reinforced concrete circular and square columns strengthened with externally applied uni-directional carbon fiber reinforced plastic material were presented. The main findings of this research can be summarized as follows:

The confinement provided by the CFRP improves both the load-carrying capacity and the ductility of the column. This method of structural rehabilitation was shown to be applicable to both circular and prismatic sections.

The failure of all CFRP wrapped specimens occurred in a sudden and explosive way preceded by typical creeping sounds. Regarding confined square columns, failure initiated at or near a corner, because of the high stress concentration at these locations.

On overall, CFRP strengthened specimens showed a typical bilinear behaviour. The first zone is essentially a linear response governed by the stiffness of the unconfined concrete. No distinct post behaviour is observed as the slenderness ratio increases.

Increasing the amount of CFRP sheets produce an increase in the compressive strength of the confined column but with a rate lower compared to that of the deformation capacity.

The efficiency of the CFRP confinement is higher for circular than for square sections, as the composite wrap was greatly affected by its premature damage at the sharp column corner.

The effect of increasing the strengthened column's slenderness ratio $(\cong 2 \div 7)$ results on overall in small effect on its load carrying and deformation capacities.

\section{Acknowledgements}

Authors thankfully acknowledge Sika France S.A, Saint-Grégoire - Rennes, for their support for providing the fiber-reinforced polymer materials.

\section{References}

1. H. Saadatmanesh, M.R. Ehsani, M.W. Li, J. ACI Struct., 91, 4, 434-447 (1994)

2. A. Nanni, N.M. Bradford, Constr. Build. Mater., 9, 2, 115-124 (1995) 
3. V.M. Karbhari, Y. Gao, J. Mater. Civ. Eng., 9, 4, 185-193 (1997)

4. A. Mirmiran, M. Shahawy, M. Samaan, H. El-Echary, J.C. Mastrapa, O. Pico, J. Compos. Constr., 2, 4, 175-185 (1998)

5. G. Campione, N. Miraglia, Cement and Concret Composites, 25, 31-41 (2003)

6. J. Berthet, E. Ferrier, P. Hamelin, Constr. Build. Mater., 19, 3, 223-232 (2005)

7. P. Rochette, P. Labossière, ASCE Journal of Composites Constructions, 4, 129-136 (2000)

8. O. Chaallal, M. Hassen, M. Shahawy, J. ACI Struct., 100, 2, 215-221 (2003)

9. Y.A. Al-Salloum, Composite Part B, 38, 640-650 (2007)

10. M. Thériault, K.W. Neale, S.J. Claude, J. Compos. Constr., 8, 4, 323-331 (2004)

11. J.L. Pan, T. Xu, Z.J. Hu, Construct. Build. Mater., 21, 1991-1996 (2007) 